\section{Perdão, confiança e amizade: Valorização dos sentimentos de dependentes químicos}

Forgiveness, trust and friendship: Valuing the feelings of chemical addicts Perdón, confianza y amistad: Valorar los sentimientos de los dependientes químicos.

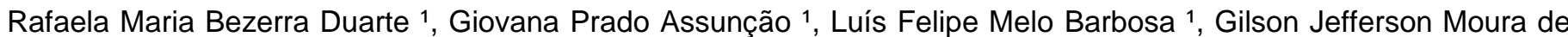
Andrade ${ }^{1}$, Tereza Angélica Lopes de Assis ${ }^{1}$

${ }^{1}$ Universidade Federal de Alagoas (UFAL), Brasil. https://doi.org/10.28998/rpss.e02106008

Recebido em: 22/01/2021

Aceito em: 10/06/2021

Disponível online: 15/06/2021

Autor Correspondente:

Rafaela Maria Bezerra Duarte

rafaelamaria.duarte@gmail.com

\title{
Resumo
}

O Projeto de Extensão AMAR: Cl pertencente à Universidade Federal de Alagoas (UFAL) tem como um de seus objetivos a Educação em Saúde para o público acometido pela dependência e abuso de substâncias psicoativas através da atuação nas comunidades terapêuticas de Maceió. Uma das ações do projeto aconteceu na Casa Betânia, comunidade terapêutica que acolhe o público feminino, e teve como objetivo a manutenção da saúde mental das acolhidas através de atividades para valorizar e fortalecer os sentimentos de perdão, confiança e amizade. Tal demanda foi percebida pelos integrantes do projeto ao conversar com as mulheres da comunidade e saber suas histórias que foram marcadas por um passado permeado pelo abandono, rejeição, violência e medo. O resultado das atividades realizadas foi contundente com a literatura científica e influenciou positivamente o bem estar desse público, mais especificamente na qualidade de saúde mental. Logo, nota-se a importância e a necessidade de realização de ações voltadas a esse público que integrem o cuidado a saúde de forma total e individualizada.

Descritores: Relação comunidade-Instituição; Transtornos Relacionados ao Uso de Substâncias; Detecção do Abuso de Substâncias.

\section{Abstract}

One of the objectives of the AMAR: CI Extension Project belonging to the Federal University of Alagoas (UFAL) is Health Education for the public affected by dependence and abuse of psychoactive substances through activities in the therapeutic communities of Maceió. One of the actions of the project took place at Casa Betânia, a therapeutic community that welcomes the female audience, and aimed to maintain the mental health of those received through activities to value and strengthen feelings of forgiveness, trust and friendship. This demand was perceived by the members of the project when talking to women in the community and knowing their stories that were marked by a past permeated by abandonment, rejection, violence and fear. The result of the activities carried out was striking with the scientific literature and positively influenced the well-being of this public, mo[1]re specifically in the quality of mental health. Therefore, it is noted the importance and the need to carry out actions aimed at this audience that integrate health care in a total and individualized way.

Descriptors: Community-Institutional Relations; Substance-Related Disorders; Substance Abuse Detection.

\section{Resumen}

Uno de los objetivos del AMAR: Proyecto de Extensión CI perteneciente a la Universidad Federal de Alagoas (UFAL) es la Educación para la Salud de la población afectada por la dependencia y abuso de sustancias psicoactivas a través de actividades en las comunidades terapéuticas de Maceió. Una de las acciones del proyecto tuvo lugar en Casa Betânia, una comunidad terapéutica que acoge al público femenino, y tuvo como objetivo mantener la salud mental de los recibidos a través de actividades para valorar y fortalecer los sentimientos de perdón, confianza y amistad. Esta demanda fue percibida por las integrantes del proyecto al conversar con mujeres de la comunidad y conocer sus historias que estuvieron marcadas por un pasado impregnado de abandono, rechazo, violencia y miedo. El resultado de las actividades realizadas fue impactante con la literatura científica e influyó positivamente en el bienestar de este público, más específicamente en la calidad de la salud mental. Por ello, se destaca la importancia y la necesidad de realizar acciones dirigidas a este público que integren la atención de la salud de forma total e individualizada.

Descriptores: Relaciones Comunidad-Institución; Trastornos Relacionados con Sustancias; Detección de Abuso de Sustancias. 
Introdução

A Atividade Multidisciplinar de Ação e Reflexão: cidadãos invisíveis (AMAR:Cl) pertencente à Universidade Federal de Alagoas (UFAL) e vinculado ao Núcleo de Saúde Pública da Faculdade de Medicina (NUSP/FAMED) possui como linha temática a Saúde e Educação. Seu público alvo são Homens e Mulheres internos das Comunidades Terapêuticas. A capacitação dos participantes e o planejamento das ações ocorrem aos primeiros sábados do mês na Faculdade de Medicina da UFAL (FAMED-UFAL) e a realização das ações nas comunidades Terapêuticas Casa Betânia e Lar servo Sofredor.

As comunidades terapêuticas são alternativas a superlotação do sistema de Centros de Atenção Psicossocial-Álcool e Drogas (CAPS-ad). Uma das referências dessas comunidades terapêuticas no estado de Alagoas é a Casa Betânia, localizada no bairro Benedito Bentes em Maceió que acolhe mulheres em situação de dependência química e vulnerabilidade social, respeitando o princípio de voluntariedade desse público na busca da recuperação da dependência química.

A Casa Betânia atua no cuidado a essas mulheres, a partir do tripé convivência, espiritualidade e laborterapia mediante a atuação de uma equipe multidisciplinar, composta por médicos, psicólogos e assistentes sociais, e realizando pontes com projetos de outras instituições de assistência à saúde do estado, como a Arquidiocese de Maceió e Projetos de Extensão da Universidade Federal de Alagoas. Contudo, em ações passadas nesse mesmo local, percebeu-se em sua estrutura determinadas carências que são relacionadas com a necessidade de compreensão das histórias dos seres humanos que ali residem, pois, por mais que o lema mais utilizado pelas acolhidas da comunidade Casa Betânia seja "Só por hoje", no sentido de viver o tempo presente intensamente, cada uma delas traz consigo um passado marcado pelo abandono, rejeição, violência e medo que culminam na dependência.

Em vista disso, atividades que promovam interações entre as residentes e que valorizem o histórico das mulheres que ali vivem, justificam-se como forma de estímulo e manutenção da saúde mental destas.

\section{Métodos}

No dia 22 de Setembro de 2018, durante o horário das 09h às $11 \mathrm{~h} 30 \mathrm{~min}$, na Comunidade Terapêutica Casa Betânia, localizada do bairro Benedito Bentes em Maceió, foi realizada uma atividade com aproximadamente 25 pessoas. A dinâmica foi dividida em 3 etapas ordenadas da seguinte maneira: 1Expressão dos sentimentos em situações de conflito e como lidar com isso ao longo do tempo; 2- Libertação de emoções ruins e atração de boas emoções e; 3Caminhada da confiança. Foram utilizados Cartolina, Imagens, Fita Adesiva, Bexigas de Assopro, Pincel Marcador e Roupas, Sapatos e Acessórios (bijuterias, cintos e bolsas). O espaço utilizado consistiu no ambiente interno (sala de televisão) e ambiente externo (jardim) da Comunidade em questão.

\section{Resultados}

A experiência relatada objetivou aflorar nas mulheres sentimentos de confiança e perdão e melhorar os vínculos de amizade de forma a aperfeiçoar a experiência de convívio. $\mathrm{Na}$ primeira etapa foi confeccionado um painel onde foram divididas duas colunas: a primeira referente ao que era feito no momento do conflito e a segunda ao que se fazia após passado algum tempo deste episódio; as mulheres deveriam descrever suas respostas utilizando-se de 2 imagens ao estilo de "Emojis" que representavam sentimentos como felicidade, tristeza, raiva, tranquilidade e desprezo, sendo cada uma afixada a coluna correspondente.

Sucessivamente, foram utilizadas bexigas cheias de água nas quais as mulheres escreveram um sentimento do qual desejavam se libertar $e$ arremessaram contra uma parede; ao realizar esse ato pronunciavam em voz alta algo de bom que desejavam alcançar. Nessa etapa, teve-se como objetivo a 
elaboração do perdão através da rememoração de sentimentos expressados por estas nos momentos em passavam por situações de conflito com terceiros e como elas lidavam com isso posteriormente.

$\mathrm{Na}$ fase seguinte, foram divididas duplas e uma das integrantes da dupla fechava os olhos; a companheira de olhos abertos guiava, então, sua parceira até um ambiente que acreditasse ser de interesse desta, para que ela se deparasse com uma bela visão; em seguida, a dupla trocava de posição e se repetia a atividade. A última etapa da consistiu em um bazar com roupas, acessórios e sapatos adquiridos através de doações dos os integrantes do projeto; as duplas da atividade anterior permaneceram unidas nessa etapa, pois, as roupas deveriam ser escolhidas por uma parceira para a acompanhante. Nessas duas últimas etapas, buscou-se fortalecer a confiança e amizade entre as acolhidas da Casa Betânia, com o intuito de fortalecer os vínculos entre elas.

\section{Discussão}

Salvo três exceções, majoritariamente as mulheres indicaram que a primeira reação ao momento de conflito era caracterizada pelo "Emoji" da raiva e as reações posteriores pela tristeza ou desprezo. $\mathrm{Na}$ literatura, destacou-se o fato de que mulheres vítimas de violência física ou psicológica pelo companheiro apresentam risco aumentado para várias morbidades psíquicas, entre elas o uso nocivo de drogas ${ }^{1}$ e de que aquelas que apresentam facilidade em perdoar os delitos que Ihe foram feitos, possuem maior bem estar ${ }^{2,3}$, o que se verifica condizente com a experiência vivenciada.

A atividade com as bexigas foi uma forma de esvaziar-se, pois, percebe-se que a materialização do sentimento ruim em um objeto e a destruição deste levou a uma real sensação de paz e tranquilidade. A caminhada de olhos fechados foi capaz de evidenciar que, a formação de vínculos e a apropriação de valores como a amizade e confiança são fatores primordiais ao amparo da saúde mental ${ }^{4}$ fatores esses também ressaltados na última etapa que proporcionou também rememoração de conceitos de beleza e autocuidado, imprescindíveis na construção da saúde mental ${ }^{5}$.

\section{Conclusão}

A valorização dos sentimentos e vínculos em indivíduos no processo de reabilitação do uso de substâncias psicoativas faz-se imprescindível como forma de lidar com flagelos passados e que ainda podem ter capacidade de açoitar a saúde mental destes. Assim, a ação relatada na Casa Betânia mostra-se justificada e eficaz, pois, tal atividade foi capaz de aliar lazer e estímulo a saúde mental ao cuidado físico e a afetividade das mulheres ali residentes mediante o tripé perdão, confiança e amizade, além de oportunizar várias experiências aos participantes do projeto. Dessa forma, mostra-se a importância da atuação de projetos voltados ao cuidado com a saúde, com o intuito de acolher de forma integral e individualizada esse público.

\section{Referências}

1. Barros, É et al. Prevalência e Fatores Associados à Violência por parceiro íntimo em mulheres de uma comunidade em Recife/Pernambuco, Brasil. Ciência \& Saúde Coletiva, V. 21, P. 5918, 2016.

2. Barros ÉND, Silva MA, Neto GHF, Lucena SG, Ponzo L, \& Pimentel AP. Prevalência e fatores associados à violência por parceiro íntimo em mulheres de uma comunidade em Recife/Pernambuco, Brasil. Ciência \& Saúde Coletiva, 2016; 21, 591-598.

3. Abdo, A. Superação X Rejeição: Aprendendo a Ser Livre. $1^{\circ}$ Edição. São Paulo: Editora Canção Nova, 2017.

4. Dutra, V; Oliveira, R. Revisão Integrativa: As Práticas Territoriais De Cuidado Em Saúde Mental. Aquichan, 2015; 15: 529-540

5. Soaigher, K; Acencio, F; Cortez, D. O Poder Da Vaidade E Do Autocuidado Na Qualidade De Vida. Cinergis, 2016; 18: 69-72

\section{Cite:}

Santos Jr, et al. Perdão, confiança e amizade: Valorização dos sentimentos de dependentes químicos. Rev. Port. Saúde e Sociedade. 2021; 6(único):e02106007. Doi:10.28998/rpss.e02106007. 